\title{
Vaginoplasty with special reference to amniongraft
}

\author{
Prof (Dr) Hem Kanta Sarma \\ Correspondence: Prof (Dr) Hem Kanta Sarma, Professor \& HOD, Department of Obstetrics \\ \& Gynaecology, Jorhat Medical College, Jorhat, Assam, India; \\ Email - sarmahemkanta@gmail.com
}

Distributed under Attribution-Non Commercial-Share Alike 4.0 International (CC BY-NC-SA 4.0)

For an unfortunate girl suffering from primary amenorrhea with absent vagina, vaginoplasty is a great remedy. It brings hope to live a normal life. Of course it has become a panacea for different types of vaginal occlusion, non canalization or total absence of vagina or non development of mullerian system. Another type of vaginoplasty in demand now a day is for transgender individuals who prefer to have female genitalia instead of a male. Besides these, there are other categories of patients needing vaginoplasty following radical surgery for genital malignancy, following difficult vaginal birth and newly married women with narrow introitus.

Vaginal abnormalities where vaginoplasty is required. ${ }^{1}$

1) Vaginal septum - Vertical or transverse, where repair involves excision of the septum followed by repair of vagina. In these conditions vaginal canal can be maintained, in most conditions without a mold or graft.

2) Narrow introitus - Fenton's operation is performed. No mould or grafting is required.

3) Imperforate hymen - Hymenotomy with a cruciate incision is usually sufficient. Mold and grafts are not required.

4) Vaginal agenesis - a) Partial agenesis of vagina is not uncommon. Upper $2 / 3^{\text {rd }}$ of vagina shows non canalization. It may be associated with hypoplasia or absence of cervix and if associated with functional uterus, it presents with hematometra. Treatment of these conditions are rather complicated \& need abdominoperineal approach for repair followed by vaginoplasty. b) Total vaginal agenesis is rare. Average incidence in the community is 1 in 4500 to 5000 women. It usually presents as a part of MRKH syndrome with a nonfunctional, small or absent uterus. Vaginal agenesis is also encountered in testicular feminising syndrome (or androgen insensitivity syndrome).
Types of vaginoplasty ${ }^{2}$

1) Bowel vaginoplasty - A segment of sigmoid colon is used as a graft maintaining the vascularity. Advantage of the procedure is due to lubrication by the sigmoid mucosa. It's not commonly used now a day.

2) Laparoscopic Davydov procedure - Laparoscopically (or by laparotomy) peritoneum is mobilized to cover the neovagina. Apex is closed by a purse string suture.

3)Vecchietti operation - A special equipment with traction device, ligature carrier and acryclic olive is used. It's performed in 2 steps and not commonly used.

4)Wharton Shears neovaginoplasty technique Continuous dilatation of the neovagina for a few months using a Balsa foam covered with a thin rubber sheath is used. It's not very popular.

5) Oxidised cellulose neovaginoplasty technique - Foam mold is covered with oxidized cellulose for dilatation of neovagina.

6) William's Vaginoplasty - In this operation a vaginal pouch is created by using full thickness skin flaps from the labia majora. This procedure is useful for post operative cases of genital malignancies.

7) McIndoe operation - In 1938, at John Hopkins Hospital, Wharton started vaginoplasty. In 1948, the counseller reported 14 cases of this procedure from Mayo clinic. Abbe used skin covered prosthesis for similar procedure much earlier. Sir Archibald McIndoe, popularized this method with extensive trial and reporting from Queen Victoria Hospital in England. In this procedure, a space is created by careful dissection between rectum and urinary bladder. This is filled with a mold (glass or sponge) covered by a partial thickness skin graft ( $20 \mathrm{~cm} \times 8 \mathrm{~cm} \times 0.018$ inch).

8) Modified McIndoe operation - Intial steps are similar to the classical McIndoe technique. Subsequently instead of a skin graft, different materials are used to substitute the 
The New Indian Journal of OBGYN. 2021 (July-December); 8(1)

graft. PACIENA prosthesis is one such example where poly lactic acid is used.

9) Vaginoplasty using amniongraft - In this procedure, the intial part is similar to the classical McIndoe Technique. After creation of the neovagina, a layer of freshly collected amnion is fixed over the mold as a graft instead of the skin graft (as in classical McIndoe operation).

This procedure has many advantages over the classical one viz ${ }^{3}$ -

a) Easy to perform (Plastic Surgeons are not required), b) Effective, c) Not having morbidities of donor areas, d) Less time consuming, e) Cost effective.

Only precaution for the procedure is to screen the donor for viral markers (viz. hepatitis B and C, HIV, VDRL).

\section{Discussion}

The author, in his own series of 17 cases performed in different institutes of Assam (North East India) from 1996 to 2020, after long term follow up (6 months to 12 year) has found very encouraging results with modified McIndoe technique using amnion graft over a mold (hard wooden, plastic, sponge or soft mold with condom filled with cotton wool). 2 of the long term followed up patients have had successful pregnancies. Others showed a functional vagina (more than $6 \mathrm{~cm}$ long) with satisfactory sexual functions. Only one patient had rectal injury during the procedure which was repaired in the same sitting with an uneventful recovery. Patients were discharged after 7 days from the hospital. Molds were changed after 7 -10 days. Repeated dilatations were performed and patients were trained to use mold for self dilatation of vagina.

In this series of 17 cases, 9 patients had non-canalisation of cervix (or absent cervix) with a functional uterus resulting in hematometra. In these cases, a neocervix was created by abdominoperineal approach followed by fixation of a tube (silastic rubber catheter) or a foley's catheter to maintain the patency of the cervix. This was subsequently withdrawn after 2 or 3 weeks. In all the cases there were positive result. Satisfactory results following amnion grafting with modified McIndoe operation was observed also by Fotopoulous et $\mathrm{al}^{4}$, Vatsa et $\mathrm{al}^{5}$, Pondel S et $\mathrm{al}^{6}$, Cetin MT et $\mathrm{al}^{7}$ and Fedele L et $\mathrm{al}^{8}$. Amnion grafting has the advantages of easy availability, minimal discomfort or morbidity to the donor area, cost effectiveness and minimal hospitalization. There is less chance of rejection of the graft in such cases.

\section{Conclusion}

Modified McIndoe technique is considered to be one of the best technique for patients with total vaginal agenesis. Amnion grafting in place of skin grafting is an advantageous option which is cheaper and with less perioperative morbidities. Of course proper care should be taken to screen the donors for viral markers and sepsis. A multicentric study involving a large number of patients will be required to justify the procedure and to improvise the techniques in near future.

Conflict of interest: None. Disclaimer: Nil.

\section{References}

1. Sharma JB. Congenital malformations of the female genital organs. Textbook of Gynaecology, $1^{\text {st }}$ edition. New Delhi: Avichal Publishing Company; 2018. p. 82-6.

2. Lesleyl B, John RA. Surgery for Anomalies of the Mullerian ducts. Te Linde's Operative Gynecology, $11^{\text {th }}$ Edition. New Delhi: WoltersKluwer; 2015. p. 505

3. Sarma HK. Amminion grafting in vaginoplasty. The New Indian Journal of OBGYN. 2020; 7(1): 1-3.

4. Fotopolous C, Lichteneggen W. Functional and anatomic results of amnion vaginoplasty in young women with Meyer -Rowkitansky - Kuster Hausen syndrome. Fertility and sterility. 2010; 94(1): 317-23.

5. Vatsa R, Bhuti J, Kumar R, Singh N, et al. Evaluation of Amnion in creation of neovagina in women with Meyer-Kuster-Hausen syndrome. Fertility and sterility. 2017; 108(2): 341- 45.

6. Paudel S, Dangal G. Amnion grafts vaginoplasty in vaginal agenesis. Journal of Christian Medical College. 2021;11(1):116-18.

7. Cetin MT, Unal E, Kadayifci O. Compassion of the modified McIndoe and modified laparoscopic Vecchietti technique for the creation of neovagina in Rokittansky syndrome. Gynaecological surgery. 2008; 5: 199-202.

8. Fedele L, Frontino G, Motta F, et al. Creation of neovagina in Rokittansky patients with a pelvic kidney; Comparison of long time results of the modified Vecchietti and McIndoe Techniques. Reproductive Surgery. 2010; 93(4): 1280-85. 